\title{
Evaluasi Kebijakan Sistem Kelas Tuntas Berkelanjutan (SKTB) di SMP Negeri 1 Pallangga
}

\author{
Mujizatullah \\ Balai Penelitian dan Pengembangan Agama Kota Makassar \\ Makassar,Indonesia \\ Email: mujizatullah@kemenag.go.id
}

\begin{abstract}
The purpose of this research is to know the Evaluation of Complete Dynamic Class System Policy (SKTB) in SMP Negeri 1 Pallangga and the factors that become supporters and obstacles in the Evaluation of Sustainable Complete Class System Policy (SKTB) At SMP Negeri 1 Pallangga. The type of this research is qualitative with informants as many as 6 people selected based on the view that informants have knowledge and information about the problems studied are: Secretary of Education Office 1 Person, Vice Principal SMP Negeri 1 Pallangga 1 Person, Teacher SMP Negeri 1 Pallangga 2 people, and Students of SMP Negeri 1 Pallangga 2 people. The data collected by using the instrument in the form of: Observation and Documentation and developed interviews to informants. The results of this study indicate that the Evaluation of the Policy of Completed Due Diligence System (SKTB) In SMP Negeri 1 Pallangga, from several indicators of effectiveness indicators, sufficiency indicators and indicators have been implemented in accordance with the Vision of Mission SMP Negeri 1 Pallangga, while the supporting factors in the evaluation of Class System policy (SKTB) In SMP Negeri 1 pallangga is, the school side responded well SKTB program, while the inhibiting factor is Module and lack of understanding of Teachers and Students.
\end{abstract}

Keywords: Policy Evaluation; Continuous Due Diligence System; (SKTB).

\begin{abstract}
Abstrak
Tujuan penelitian ini adalah untuk mengetahui Evaluasi Kebijakan Sistem Kelas Dinamis Lengkap (SKTB) dan faktor-faktor yang menjadi pendukung dan penghambat dalam Kebijakan Sistem Kelas Lengkap Berkelanjutan (SKTB) Di SMP Negeri 1 Pallangga. Metode Penelitian yang digunakan ialah kualitatif dengan informan sebanyak 6 orang yang dipilih berdasarkan pandangan bahwa informan memiliki pengetahuan dan informasi mengenai permasalahan yang diteliti yaitu : Sekretaris Dinas Pendidikan 1 Orang, Wakil Kepala Sekolah SMP Negeri 1 Pallangga 1 Orang, Guru SMP Negeri 1 Pallangga 2 orang, dan Siswa SMP Negeri 1 Pallangga 2 orang. Data yang dikumpulkan dengan menggunakan instrumen berupa :Observasi dan Dokumentasi dan dikembangkan wawancara terhadap informan. Fakta dilapangan menunjukkan bahwa Evaluasi Kebijakan Sistem Kelas Tuntas Berkelanjutan (SKTB) Di SMP Negeri 1 Pallangga, dari beberapa indikator yaitu indikator efektivitas, indikator kecukupan dan indikator ketetapan sudah dilaksanakan sesuai Visi Misi SMP Negeri 1 Pallangga, sedangkan faktor pendukung dalam evaluasi kebijakan Sistem Kelas Tuntas Berkelanjutan (SKTB) Di SMP Negeri 1 pallangga adalah, Pihak sekolah merespon dengan baik program SKTB, Sedangkan faktor penghambatnya adalah Modul dan kurangnya pemahaman Guru dan Siswa.
\end{abstract}

Kata Kunci: Evaluasi Kebijakan; Sistem kelas Tuntas Berkelanjutan; (SKTB).

Link DOI : http://dx.doi.org/10.31314/pjia.7.1.22-28.2018 


\section{PENDAHULUAN}

Evaluasi adalah kegiatan untuk menilai tingkat kinerja suatu kebijakan. Dan kebijakan baru dapat dilakukan apabila suatu kebijakan sudah berjalan cukup waktu. Memang tidak ada batasan waktu yang pasti kapan suatu kebijakan harus di evaluasi, untuk mendapat outcomedan dampak suatu kebijakan sudah tentu diperlukan waktu tertentu, misalnya 5 tahun semenjak kebijakan itu diimplementasikan, sebab kalau evaluasi dilakukan terlalu dinamika outcome dan dampak dari suatu kebijakan belum nampak. Semakin strategis suatu kebijakan, maka diperlukan tenggang waktu yang lebih panjang untuk melakukan evaluasi. Oleh karena itu yang dimaksud dengan evaluasi adalah kegiatan atau proses untuk mengukur dan selanjutnya menilai sampai dimanakah tujuan yang telah dirumuskan sudah dapat dilaksanakan, (Dye dalam Nawawi , 2009) evaluasi kebijakan merupakan kegiatan untuk menilai atau melihat keberhasilan atau kegagalan pelaksanaan suatu kebijakan publik, oleh karena itu, evaluasi merupakan kegiatan pemberian nilai atas sesuatu "fenomena" didalamnya terkandung pertimbangan nilai (valuejudgment) tertentu, ( Mustopadijaja , 2002). Evaluasi sendiri bertujuan untuk mengumpulkan, menganalisis, dan menyajikan informasi yang bermanfaat mengenai objek evaluasi, menilainya dengan membandingkannya dengan indikator dan hasilnya dipergunakan untuk mengambil keputusan mengenai objek evaluasi, (Akbar,MF,2016).

Sesuai dengan Peraturan Daerah Kabupaten Gowa Nomor 10 tahun 2013 Tentang Sistem Kelas Tuntas Berkelanjutan di Kabupaten Gowa berupaya memberikan pelayanan pendidikan secara optimal kepada peserta didik. Mendiskusikan pendidikan dalam ranah kebijakan merupakan persoalan yang perlu mendapatkan perhatian serius oleh pemerintah dan masyarakat. Dari aspek sosial masyarakat, pendidikan berarti pewarisan kebudayaan dari generasi tua kepada generasi muda, agar kehidupan masyarakat tetap berkelanjutan, atau dengan kata lain masyarakat mempunyai nilai budaya yang disalurkan kepada generasi muda (Harakan, 2017).

Maka melalui stategi penuntasan semua tagihan standar kompetensi dan kompotensi dasar pada setiap mata pelajaran secara berkelanjutan. (Perda Nomor 10 Tahun 2010 Tentang Sistem Kelas Tuntas Berkelanjutan). SKTB merupakan singkatan dari Sistem Kelas Tuntas Berkelanjutan (Automatic Promotion), SKTB disosialisasikan pada tahun 2011 dimana pelaksanaanya pada tahun 2012 dan pada 2013 dilaksanakan secara keseluruhan disemua tingkatan sekolah SD, dan SMP di Kabupaten Gowa.

Kualitas pelayanan pendidikan di sekolah adalah sejauh mana sekolah dapat menunjukkan ketersediaan, kelengkapan, kelayakan sarana dan prasarana sekolah, tenaga pendidik dan tenaga kependidikan, reliabilitas tenaga pendidik, responsivitas tenaga pendidikan dalam melaksanakan pelayanan, kepastian dalam pelayanan, dan sikap empati dalam pelayanan pendidikan di sekolah (Basri, 2011). Maka Sebagai langkah awal, SKTB dijalankan di beberapa sekolah percontohan tepatnya 50 sekolah untuk tingkatan SD, dan SMP di Kabupaten Gowa. SKTB adalah kebijakan program pendidikan yang berupaya memberikan pelayanan pendidikan secara optimal kepada peserta didik melalui strategi penuntasan semua tagihan standar kompetensi dan kompetensi dasar pada setiap mata pelajaran secara berkelanjutan. SKTB berfungsi mengembangkan kemampuan dan membentuk watak serta peradaban bangsa yang bermartabat dalam Copyright @ 2018, Publik : (Jurnal Ilmu Administrasi), ISSN: 2301-573X (Print), ISSN: 2581-2084 (Online) 
rangka mencerdaskan kehidupan bangsa. Tujuan yang hendak dicapai dengan SKTB adalah memberikan pelayanan pendidikan secara maksimal pada anak didik, agar dapat belajar secara optimal dalam menuntaskan semua tagihan kompetensi pada seluruh mata pelajaran di setiap satuan pendidikan dan membantu memfasilitasi pengembangan potensi anak didik secara utuh (kecerdasan spiritual, kecerdasan emosional, kecerdasan intelektual dan kecerdasan kinestetik) sejak awal agar terbentuk kepribadian yang utuh. (Buku Panduan Sistem Kelas Tuntas Berkelanjutan)

\section{METODE PENELITIAN}

Tipe dan jenis penelitian yang digunakan adalah kualitatif dengan pendekatan deskriptif untuk menggambarkan suatu fenomena atau kenyataan sosial, yang berkaitan dengan masalah yang diteliti, khususnya Evaluasi Kebijakan Sistem Kelas Tuntas Berkelanjutan (SKTB) Di SMP Negeri 1 Pallangga. Waktu pelaksanaan dilakukan pada tanggal 07 Oktober - 07 Desember 2017. Penelitian dilakukan di Kabupaten Gowa dengan lokasi penelitian dilaksanakan pada Dinas Pendidikan Kabupaten Gowa dan SMP Negeri 1 Pallanngadengan dasar pertimbangan karena pelaksana dari Program Sistem Kelas Tuntas Berkelanjutan (SKTB).

\section{HASIL DAN PEMBAHASAN}

Ditinjau dari segi tujuan studi evaluasi bahwa tujuan evaluasi adalah mengumpulkan informasi untuk menentukan nilai dan manfaat objek evaluasi, mengontrol, memperbaiki, dan mengambil keputusan menganai objek tersebut, (Akbar,MF,Mohi,WK,2018).

William N Dunn (dalam Riant Nugroho, 2009), Untuk menilai keberhasilan suatu kebijakan perlu dikembangkan beberapa indikator, karena penggunaan indikator yang tunggal akan membahayakan, dalam arti hasil penilaiannya dapat bisa dari yang sesungguhannya. Indikator atau kriteria evaluasi mencakup lima evaluasi sebagai berikut:

1. Efektifitas (effectivenss) berkenaan apakah suatu alternatif mencapai hasil (akibat) yang di harapkan atau mencapai tujuan dari diadakannya tindakan.

2. Kecukupan (adequacy) berkenaan dengan seberapa jauh suatu tungkat efektifitas memuaskan kebutuhan, nilai atau kesempatan yang menumbuhkan adanya masalah. Kriteria kecukupan menekankan pada kuatnya hubungan antara alternatif kebijakan dan hasil yang diharapkan

3. Ketetapan (apporopriateness) adalah kriteria ketetapan secara dekat yang berhubungan dengan rasionalitas subtansif, karena pertanyaan tentang ketetapan kebijakan tidak berkenaan dengan suatu kriteria secara bersama-sama. Ketetapan merujuk pada nilai atau harga diri tujuantujuan program dan kepada kuatnya asumsi yang melandasi tujuan tersebut.

$$
\text { Evaluasi Kinerja kebijakan }
$$
diakukan untuk menilai hasil yang dicapai oleh suatu kebijakan setelah dilaksanakan. Hasil yang dicapai dapat diukur dalam ukuran jangka pendek atau output, jangka panjang atau outcome. Evaluasi kinerja kebijakan dengan melakukan penilaian komprehensif terhadap:

1. Pencapain target (output)

2. Pencapaian tujuan kebijakan (outcome)

3. Kesenjangan (gap) antar target dan tujuan dengan pencapaian

4. Perbandingan (benchmarking) dengan kebijakan yang sama di tempat lain yang berhasil. 
Publik : (Jurnal Ilmu Administrasi) Vol 7 (1), Juni 2018

Jurnal IImu Administrasi

5. Indentifikasi faktor pendukung

keberhasilan dan kegagalan sehingga

menyebabkan kesenjangan, dan memberikan rekomendasi untuk menanggulangi kesenjangan.

Evaluasi memiliki beberapa tujuan menurut Subarsono (2005) yang dapat dirinci sebagai berikut:

a. Menentukan tingkat kinerja suatu kebijakan. Melalaui evaluasi maka dapat diketahui derajat pencapaian tujuan sasaran kebijakan.

b. Mengukur tingkat efesiensi suatu kebijakan. Dengan evaluasi juga dapat diketahui beberapa biaya dan manfaatdari suatu kebijakan.

c. Mengujur tingkat keluaran (outcome) suatu kebijakan. Salah satu tujuan evaluai adalah mengukur beberapa besar dan kualitas pengeluaran (output) dari suatu kebijakan.

d. Mengukur dampak dari suatu kebijakan. Pada tahap lebih lanjut,evaluasi ditujukan untuk melihat dampak dari suatu kebijakan,baik dampak positif maupun dampak negatif.

e. Untuk mengetahui apabila ada penyimpanan,evaluasi juga bertujuan untuk mengetahui adanya penyimpanganpenyimpangan yang mungkin terjadi,dengan cara membandingkan antara tujuan dan sasaran dengan pencapaian target.

f. Sebagai bahan masukan (input) untuk kebijakan yang akan datang. Tujuan akhir dari evaluasi kebijakan adalah untuk memberikan masukan bagi proses kebijakan kedepan agar dihasilkan kebijakan-kebijakan yang lebih baik.

Sistem Kelas Tuntas Berkelanjutan atau yang disingkat SKTB adalah proses pembelajaran yang mengembangkan potensi peserta didik untuk mencapai kualitas kemampuan yang dipersyaratkan kurikulum.
Sistem pembelajaran kelas tuntas berkelanjutan bertujuan :

1. Memberikan kesempatan kepada semua peserta didik untuk menguasai semua kompetensi sebagaimana dinyatakan dalam standar kompetensi dan Kompetensi Dasar serta dirumuskan dalam Nilai Kompetensi Kelas Minimal.

2. Memberikan pelayanan pendidikan secara maksimal pada anak didik dalam suasana pendidikan yang kondusif.

3. Memberikan kesempatan kepada peserta didik yang dapat menuntaskan penguasaan semua kompetensi dasar pada setiap mata pelajaran sebelum waktunya untuk diberikan kesempatan mengambil kompetensi dasar berikutnya tanpa harus menunggu tahun pelajaran berikutnya/masa kenaikan kelas.

4. Membantu dan memfasilitasi pengembangan potensi peserta didik secara utuh (kecerdasan spritual, kecerdasan emosional (intrapersonal), kecerdasan intelektual, kecerdasan sosial (interpersonal), kecerdasan musikal dan kecerdasan kinestik). Untuk pembentukan kepribadian bermoral, sejak usia dini sampai akhir hayat dalam rangka mewujudkan masyarakat belajar.

5. Meningkatkan keprofesionalan dan akuntabilitas lembaga pendidikan sebagai pusat pembudayaan ilmu pengetahuan, keterampilan, pengalaman, sikap, dan nilai berdasarkan standar nasional dan global.

Berikut akan dibahas hasil dari penelitian mengenai evaluasi Sistem Kelas Tuntas Berkelanjutan (SKBT) di SMP Negeri 1 Palangga, berdasarkan kriteria yang telah dijelaskan oleh Dunn.

\section{Efektifitas (effectiveness)}

Program Sistem Kelas Tuntas Berkelanjutan (SKTB) susah tecapai akan tetapi masih ada 1 tujuan program yang belum tercapai yaitu meningkatkankeprofesionalan dan akuntabilitas lembaga pendidikan sebagai Copyright @ 2018 , Publik : (Jurnal Ilmu Administrasi), ISSN: 2301-573X (Print), ISSN: 2581-2084 (Online) 
pusat pembudayaan ilmu pengetahuan, keterampilan, pengalaman, sikap dan nilai berdasarkan standar nasional dan global tidak tercapai sesuai dengan harapan karena kinerja Dinas maupun pihak sekolah yang ingin dicapai belum terpenuhi dengan baik, karena Dinas juga menginginkan agar program SKTB ini berjalan sesuai dengan harapan.

2. Kecukupan (adequacy)

Program Sistem Kelas Tuntas Berkelanjutan Dilaksanakan disemua tingkatan sekolah dikabupaten Gowa tepatnya SD maupun SMP, dimana program yang mampu memfasilitasi pengembangan potensi peserta didik secara utuh(kecerdasan spiritual, kecerdasan intelektual, kecerdasan sosial, kecerdasan berbahasa),selain itu para stakeholder harus bekerja sama sesuai tugas dan fungsinya masing-masing dalam menjalankan program tersebut sesuai dengan harapan pemerintah.

\section{Ketetapan (apporopriateness)}

Kondisi sebelum adanya SKTB dikabupaten Gowa yaitu daerah ini masih menganut model pendidikan yang berlaku dibanyak daerah yaitu masih mengenal adanya peserta didik (siswa) yang tinggal kelas, namun setelah adanya SKTB untuk kabupaten Gowa tidak mengenal lagi adanya tinggal kelas bagi peserta didik (siswa). Ketika ada pembelajaran yang tidak tuntas pada kelas sebelumnya, maka peserta didik (siswa) tersebut tidak harus mengulang semua mata pelajaran pada kelas tersebut, melainkan peserta didik itu naik kelas dan hanya melakukan remedial pada mata pelajaran yang tidak tuntas. Adapun fasilitas sekolah yang menjadi penunjang yaitu jumlah tenaga pendidik yang memadai, jumlah laboratorium yang memadai, lapangan sekolah ,ruangan pustakawan, mushollah, lahan yang memadai dll, selain itu ada juga fasilitas sekolah yang belum memadai yaitu jumlah kelas yang tersedia tidak sebanding dengan jumlah rombongan belajar.

4. Pihak sekolah merespon dengan baik program SKTB

Sistem Kelas Tuntas Berkelanjutan (SKTB) telah mendapat respon yang baik dan telah diterima baik dari guru maupun peserta didik (siswa) itu sendri, karena apabila ada peserta didik yang belum tuntas maka diberikan remedial sampai pesera didik mencapai ketuntasan. Sehingga peserta didik dapat melakukan percepatan dalam studinya.

5. Modul Yang Belum Siap

Penghambat dalam Sistem Kelas Tuntas Berkelanjutan adalah Modul yang belum siap, sehingga Siswa belum mendapatkan paket pengajaran untuk diri mereka sendiri.

6. Kurangnya pemahaman Guru dan peserta didik (Siswa)

Guru maupun peserta didik (Siswa) belum memahami betul tentang Program Sistem Kelas Tuntas Berkelanjutan( SKTB), dimana kurangnya sosialisasi dan tingkat kesadaran yang rendah dalam pelaksanaan SKTB yang kurang tidak cuman itu saja yang menjadi faktor penghambat kurangnya respon dari Guru ada yang pro dan kontra sehingga tingkat pemahaman terkait program SKTB masih rendah.

\section{PENUTUP}

\section{Kesimpulan}

Berdasarkan hasil wawancara dan pembahasan pada bab sebelumnya terkait Evaluasi Kebijakan Sistem Kelas Tuntas Berkelanjutan di SMP Negeri 1 Pallangga maka dapat disimpulkan sebagai berikut: Bahwa Evaluasi kebijakan Sistem Kelas Tuntas Berkelanjutan (SKTB) di SMP Negeri 1 Pallangga, untuk mewujudkan hal 
tersebut dilakukan evaluasi kebijakan efektifitas, kecukupan, ketetapan. Dilihat dari beberapa indikator diatas dapat disimpulkan : a. Efektifitas hasil yang ingin dicapai sudah maksimal hanya saja masih ada 1 tujuan program yang belum terlaksana. b kecukupan dengan adanya program SKTB masih dikembangkan agar program ini diketahui oleh setiap kalangan untuk perkembangan dan kemajuan program SKTB. c ketetapan dalam hal ini sudah tetap sasaran, dimana kondisi sebelum SKTB peserta didik masih tinggal kelas, namun setelah adanya SKTB tidak ada lagi peserta didik yang tinggal kelas. faktor yang mempengaruhi Evaluasi Kebijakan Sistem Kelas Tuntas Berkelanjutan (SKTB) di SMP Negeri 1 Pallangga antara lain faktor pendukung adalah, Pihak sekolah merespon dengan baik program SKTB itu sendiri sedangkan faktor penghambat yaitu modul yang belum siap, dan kurangnya pemahaman guru maupun peserta didik (siswa).

Saran

Adapun saran-saran yang penulisan berikan dari hasil penelitian yang dilakukan selama penelitian adalah sebagai berikut :

- Perlunya meningkatkan koordinasi yang baik antara Guru dan peserta didik (siswa) sehingga program kebijakan yang dikeluarkan oleh Dinas pendidikan dapat berjalan sesuai yang diharapkan.

- Pelaksanaan kebijakan SKTB lebih ditingkatkan pengawasanya selain memberikan kelulusan yang tinggi, namun tetap memperhatikan kualitas pelaksanaan kebijakannya.

- Hendaknya ada pembinaan dan bimbingan khusus bagi seluruh guru yang terlibat sebagai pelaksanaan program kerja yang dikeluarkan oleh dinas pendidikan.
- Guru perlu meningkatkan dan memberikan pemahaman kepada peserta didik (siswa) mengenai SKTB, agar tidak terjadi kesalahpahaman.

- Program SKTB seharusnya tidak dilaksanakan lagi/dilanjutkan di sekolah baik SD, maupun SMP,karena banyak peserta didik yang masa bodoh (malas saja naik kelas apa lagi kalau rajin).

\section{DAFTAR PUSTAKA}

Agustino, Leo. (2006). Dasar-dasar kebijakan publik. Bandung: Alfabeta Akbar,MF. (2016). Evaluasi Kebijakan Program Pemberian Dana Bantuan Operasional Sekolah. JAKPP UNHAS. 2(1),47-64

Akbar,MF, Mohi,WK. (2018). Studi Evaluasi Kebijakan (Evaluasi Beberapa Kebijakan di Indonesia). Gorontalo : Ideas Publishing

AR.Mustopadidjaja. (2002). Manajemen Proses Kebijakan Publik Formulasi Implementasi dan Evaluasi Kinerja. Jakarta: LAN

Basri, M. (2011). Budaya Mutu Dalam Pelayanan Pendidikan. Otoritas: Jurnal Ilmu Pemerintahan, 1(2).

Harakan, A. (2017). Efektivitas pelaksanaan kebijakan sistem kelas tuntas berkelanjutan di kabupaten Gowa. ARISTO, 5(1), 101-109.

Luankali, Bernadus. (2007). Analisis Kebijakan Publik dalam proses pengambilan keputusan. Jakarta : Amelia.

Mattewakkang, Anugrah. (2014). Persepsi Guru SMA Negeri 1 Bontomarunnu Tentang Sistem Kelas Tuntas Berkelanjutan di Kabupaten Gowa. Jurnal Sosialisasi 1, (1).

Mustari, Nuriyanti, (2005). Pemahaman Kebijakan Publik. Formulasi, Implementasi, dan Evaluasi Copyright $@$ C 2018, Publik : (Jurnal Ilmu Administrasi), ISSN: 2301-573X (Print), ISSN: 2581-2084 (Online) 
Kebijakan Publik. Yogyakarta : PT Leutika Nouvalitera.

Mustari, Nuryanti, (2013). Implementasi Kebijakan Publik. Pemahaman Teoritis, Empiris. Jakarta: Membumi Publishing.

Putra, Fadillah. (2003). Paradigma Kritis dalam studi Kebijakan Publik. Yogyakarta: Pustaka Pelajar.

Subarsono, AG. (2005). Analisis Kebijakan Publik Konsep, Teori, dan Aplikasi. Yogyakarta: Pustaka Pelajar.

Sugiyono. (2012). Memahami Penelitian Kualitatif. Bandung: ALFABETA.

Winarno, Budi. (2008). Teori Kebijakan Publik, teori,proses dan studi kasus. Jakarta : CAPS.PT. Buku Seru 